\title{
Delirium Revealing a Parathyroid Adenoma
}

\section{Jebbar Nourddine ${ }^{12 *}$, , Elkaissi Jaber ${ }^{1},{ }^{2}$, Maaroufi Ayoub ${ }^{1},{ }^{2}$, Diai Abdellatif ${ }^{1},{ }^{2}$, Jbili Nabil ${ }^{1},{ }^{2}$, Bibiche Lotfi $^{1},{ }^{2}$, Kechna} Hicham $^{12},{ }^{2}$, Laoutid Jaouad ${ }^{12}$

${ }^{1}$ Anesthesiology \& intensive care department, Moulay Ismail Military Hospital, Meknes, Morocco

${ }^{2}$ Faculty of Medicine, Sidi Mohamed Ben Abdellah University, Fes, Morocco

DOI: $10.36347 /$ sjmcr.2021.v09i04.045

| Received: 18.03.2021 | Accepted: 25.04.2021 | Published: 30.04.2021

*Corresponding author: Jebbar Nourddine MD

\section{Abstract}

Primary hyperparathyroidism is quite common. The most forms are now seen in women after menopause and appear to have little evolution. Support surgery is imperative for primary hyperparathyroidism occurring before age 50 , and in symptomatic forms, especially in cases of bone loss.

Keywords: Parathyroid, Delirium Revealing.

Copyright $\odot 2021$ The Author(s): This is an open-access article distributed under the terms of the Creative Commons Attribution 4.0 International License (CC BY-NC 4.0) which permits unrestricted use, distribution, and reproduction in any medium for non-commercial use provided the original author and source are credited.

\section{INTRODUCTION}

Primary hyperparathyroidism (HPT) has long been considered like a rare disease, responsible for pain, pathological fractures, and resulting in appalling deformations. The severity of the disease was further aggravated by the nephrological risk complicating recurrent kidney stones.

Primary hyperparathyroidism is now a disease frequent: its incidence has been estimated at 27 new cases per 100,000 inhabitants in New York [1], its prevalence reached 1 in 1,000 subjects [2].

Affection predominates now largely in women after the age of menopause, this explained by the revealing effect of estrogen deficiency on osteoblastic activity.

In this population in particular, the majority of the forms observed are asymptomatic, fortuitously discovered by the measurement of calcium. Surgery, on the other hand, remains essential in young subjects and in symptomatic and progressive forms.

It is in these circumstances particularly justified by a double investigation etiological and morphological. Recognition of predisposition genetics and the exact location of pathological parathyroids now modulate the practical modalities of intervention and monitoring.

\section{CASE RePORT}

This is a 69-year-old patient with a history of type 2 diabetes on metformin and gout on allopurinol, admitted on February $25^{\text {th }} 2021$ in intensive care for afebrile disorder of consciousness. The onset of symptoms dates back to February $15^{\text {th }} 2021$ with the onset of abdominal pain with incoercible vomiting. The evolution was marked by the installation of a disturbance of consciousness and the patient was admitted to us for treatment. On admission the patient was confused with a Glasgow score of $10 / 15$, brainstem reflexes present with equal and responsive pupils. Hemodynamically, the patient had a blood pressure of $120 / 76$ with a heart rate of $89 \mathrm{bpm}$. The patient was eupneic and $98 \%$ saturated with ambient air. A brain scan was performed returning normal. A biological assessment objectified a malignant hypercalcemia at $177 \mathrm{mg} / \mathrm{1}$, a parathyroid hormone level at 899pg / ml, natremia at $144 \mathrm{mmol} / 1$ and renal failure with creatinine at $25 \mathrm{mg} / \mathrm{dl}$. An electrocardiogram showed a shortening of the QT space. The patient was put under rehydration with $9 \%$ saline serum (500CC / 4 hours), bisphosphonate, furosemide $(20 \mathrm{mg} / 12 \mathrm{H})$, gastric protection, anticoagulation preventive dose ,corticosteroids and vitamin D. The evolution was marked by a slight improvement on the neurological level with decrease in the corrected calcium level (81 $\mathrm{mg} / \mathrm{l}$ ) and the level of parathyroid hormone (147 pg / $\mathrm{ml}$ ) with the appearance of hypernatremia at $160 \mathrm{mmol}$ / 1 ; the patient was placed under tap water with correction of the natremia at the end of 48 hours. A cervical ultrasound was performed objectifying a large right parathyroid nodule measuring $24 \mathrm{~mm}$ for which the patient was operated. Pathological examination revealed that it was a parathyroid adenoma (Figure 1). 


\section{DisCUSSION}

\section{Pathophysiology}

Parathyroid hormone elevates serum calcium, increasing the bone remodeling and predominantly osteolysis, by promoting renal tubular reabsorption of calcium and increasing intestinal absorption of calcium; this last action is indirect, is carried out by activating the 1 $\square \square$-renal hydroxylase and production of 1,25$(\mathrm{OH}) 2$ cholecalciferol. Parathyroid hormone is phosphodiuretic and reduces renal elimination of $\mathrm{H}$ ions+ .Hyperparathyroidism hypercalcemia primary coincides with hypophosphatemia, a tendency to hyperchloraemic acidosis and urine alkalization. Despite increased tubular reabsorption of calcium, high calciuria, due to the increased fraction filtered by the glomerulus. The severity of primary hyperparathyroidism is not simply linked to increased functional parenchymal mass. It is also a function of the sensitivity of the parathyroid cells to feedback control by calcemia, and the degree at this level calcium receptor expression [2]. At the initial stage, hypercalcemia is primarily the result of increased reabsorption tubular calcium, and not resorption, as during other situations of hypercalcemia of nonparathyroid origin [2]. Finally, an important factor in the expression of hyperparathyroidism primary is constituted by the vitamin load $\mathrm{D}$. The relative deficiency of vitamin $\mathrm{D}$ indeed leads to defect absorption of calcium from the intestine, promotes increased PTH levels, and overall increases the severity of bone damage [3].

Clinical manifestations: table I

Table-I: Primary hyperparathyroidism: revealing manifestations (In JL Wemeau Horm Res 1989) in a Lille series of 622 operated patients $(4)$

\begin{tabular}{|l|l|l|}
\hline symptoms & Number of cases & $\mathbf{\%}$ \\
\hline Renal lithiasis & 160 & 25,7 \\
Bone pain & 57 & 9,2 \\
Fractures & 4 & 0,6 \\
Peptic ulcers & 8 & 1,3 \\
Acute pancreatitis & 7 & 1,1 \\
Arterial hypertension & 10 & 1,6 \\
Rythm disturbances & 3 & 0,6 \\
Renal failure & 8 & 1,3 \\
Asthenia & 30 & 4,8 \\
Polyuria & 4 & 0,6 \\
Acute hypercalcemia & 40 & 6,4 \\
Other signs : determination of & 57 & 9,2 \\
calcemia & \\
Preoperative assessment of a goiter & 62 & 10 \\
Systematic dosage & 168 & 27 \\
& &
\end{tabular}

Causes: table II (5)

Table-II: Causes of hypercalcemia

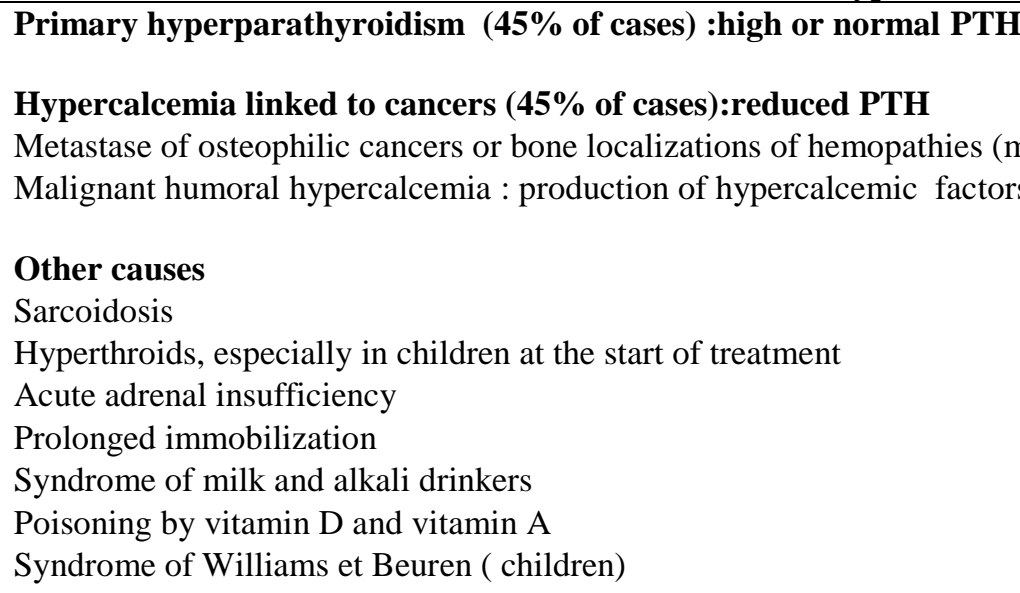




\section{Treatment}

In any patient suspected of primary HPT, before any investigation morphological in search of the location and before any project surgical. It seems important to assess in all patients the vitamin D load, by the systematic measurement of 25hydroxycholecalciferol. Vitamin D deficiency, especially by default intake and sunshine, particularly sensitive in patients with pigmented skin and in the northern regions, in fact profoundly modifies the diagnostic presentation and progressive disease.
Patients are exposed to elevation higher PTH level, at a high risk of demineralization and also to severe and prolonged hypocalcemic crises after surgical cure of the disease. It appeared that supplementation of these subjects deficient by physiological doses of vitamin D under biological monitoring, reduces the rates of PTH, improves bone mass, with little risk of increase calcemia or calciuria. Finally we must discuss with patients the merits either intervention in principle or abstention immediate surgery, at the cost of strict monitoring [5].

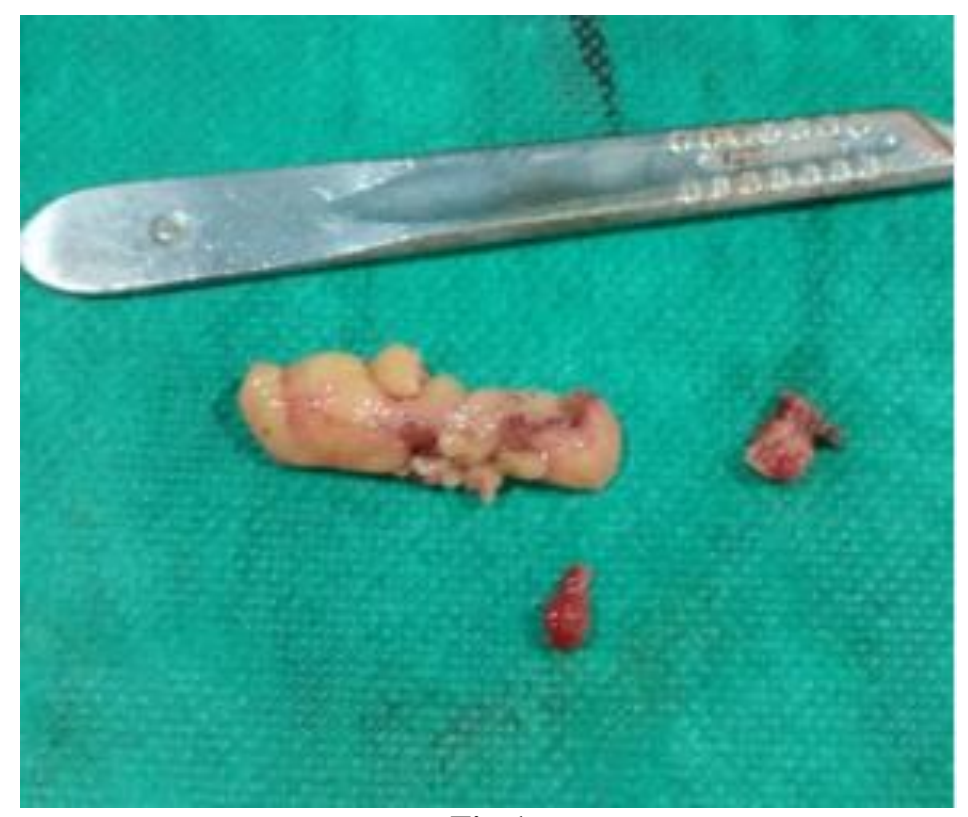

Fig-1

\section{REFERENCES}

1. Heath H 3rd, Hodgson SF, Kennedy MA. Primary hyperparathyroidism. Incidence, morbidity, and potential economic impact in a community. N Engl J Med. 1980; 302:189-93.

2. Houillier P, Maruani G, Eladari D, Paillard M. Hyperparathyroïdie primitive. Encl Méd Chir (Editions Scientifiques et Médicales Elsevier SAS, tous droits réservés), Endocrinologie-Nutrition, 10012-B-10, 2002, 9 p.
3. Silverberg SJ, Shane E, Dempster DW, Bilezikian JP. The effects of vitamin D insufficiency in patients with primary hyperparathyroidism. Am J Med. 1999;107:561-7.

4. Wémeau JL, Gilliot-Valtille E, Bizard JP. Current concepts in primary hyperparathyroidism. Horm Res. 1989; 32:93-6.

5. Clinique Endocrinologique Marc Linquette, CHU de Lille, 6 rue du Professeur Laguesse, 59037 Lille cedex, France. Correspondance : J-L Wémeau, 